\section{Clinical research training of Peruvian neurologists: a baseline assessment}

\author{
Gian Carlos Navarro-Chumbes,' \\ Silvia Margarita Montano-Torres, ${ }^{2}$ \\ Alberto Díaz-Vásquez, ${ }^{3}$ \\ Joseph Raymond Zunt ${ }^{4}$ \\ 'School of Public Health and \\ Administration, Universidad Peruana \\ Cayetano Heredia, Lima, Peru; \\ ${ }^{2}$ Naval Medical Research Center \\ Detachment, Lima, Peru; \\ ${ }^{3}$ E. Rebagliati Hospital, EsSalud, Lima, \\ Peru; \\ ${ }^{4}$ Departments of Neurology, Global \\ Health, Medicine (Infectious Diseases) \\ and Epidemiology, University of \\ Washington, Seattle, WA, USA
}

\section{Abstract}

In Peru, despite a strong clinical research infrastructure in Lima, and Masters degree programs in epidemiology at three universities, few neurologists participate in clinical research. It was our objective to identify perceived needs and opportunities for increasing clinical research capacity and training opportunities for Peruvian neurologists. We conducted a descriptive, cross-sectional survey of Peruvian neurologists in Lima and Arequipa, Peru. Forty-eight neurologists completed written surveys and oral interviews. All neurologists reported interest in clinical research, but noted that lack of time and financial resources limited their ability to participate. Although most neurologists had received some training in epidemiology and research design as medical students or residents, the majority felt these topics were not adequately covered. Neurologists in Arequipa noted international funding for clinical research was uncommon outside the capital city of Lima. We concluded that clinical research is important to Peruvian neurologists. The three main barriers to increased participation in clinical research identified by neurologists were insufficient training in clinical research methodology, meager funding opportunities, and lack of dedicated time to participate in clinical research. Distance learning holds promise as a method for providing additional training in clinical research methodology, especially for neurologists who may have difficulty traveling to larger cities for additional training.

\section{Introduction}

Evidence-based medicine is "the conscientious, explicit, and judicious use of current best evidence in making decisions about the care of individual patients." Scientific and technological advances in clinical research enhance the practice of evidence-based medicine but this research focuses almost exclusively on diseases and conditions affecting people living in resource rich countries. ${ }^{2,3}$ To increase knowledge of endemic infections and diseases of regional and global importance, clinical neurological research in developing countries is necessary. ${ }^{4}$ Unfortunately, resources to train clinical researchers in developing countries are often limited.

Development of clinical researchers in any country requires mentoring, training in research methodology, bioethics, data analysis, and many other research-related activities. ${ }^{5}$ The Institute of Medicine noted five barriers to successful development of a career in clinical research: lack of protected time, insufficient training in research methodology, lack of mentors, emphasis on basic science rather than patient-oriented research; and high student debt. ${ }^{5}$ In the developing world, these barriers are accompanied by a paucity of robust information regarding diseases endemic to the country, lack of access to medical literature, a weak or nonexistent research infrastructure, and low physician wages., ${ }^{4,-8}$ In addition, in resource-poor countries such as Peru, most physicians receive compensation only for patient care and teaching activities; opportunities to receive compensation for conducting clinical research are limited, and few neurologists participate in clinical research. ${ }^{9}$

Distance learning provides a practical solution to overcoming the time, expense, and geographical barriers of traditional classroom training. Web-based tools allow didactic content delivery, collaborative projects, assessments and evaluations at times convenient to trainees; trainees can take part in synchronous or asynchronous chat-room discussions with other trainees and instructors and use on-line resources in conjunction with live training sessions to reduce training time. ${ }^{10}$ Compared to classroom training, students rate web-based training equivalent in terms of knowledge gained, but some studies report less satisfaction with instructor rapport. ${ }^{11,12}$ Studies in the field of neurology report webbased simulated clinical encounters may be more effective than traditional teaching methods for teaching core competencies and clinical skills. ${ }^{13,14}$ Although many neurological societies and universities offer web-based resources, training opportunities, and recorded lectures, programs for teaching clinical research on-line are not widely available
Correspondence: Joseph Raymond Zunt, Harborview Medical Center, Department of Neurology, P.0. Box 359775, 325 Ninth Avenue South, Seattle, WA 98104, USA.

E-mail: jzunt@u.washington.edu

Key words: clinical research, training, neurology, global health, Peru, evidence-based medicine.

Acknowledgements: funding was provided to Joseph R. Zunt by NIH Fogarty International Center and NINDS (R21 NS048838 and R01 NS055627), and NIAID (K23-AI01600, University of Washington Center for AIDS Research (CFAR AI27757). We thank Dr. Peggy Martinez and Dr. Carlos Caparó for their unselfish collaboration in conducting this study; and the chiefs of sections and neurologists at the following sites, whose patience, dedication and unselfishness made this study possible, Lima: Institute of Neurological Sciences, Ministry of Health, E. Rebagliati Hospital (EsSalud), Air Force Central Hospital, Stella Maris Private Hospital, a private doctor's office; Arequipa: Honorio Delgado National Hospital, Ministry of Health, Carlos Alberto Seguin Hospital (EsSalud), III Yanahuara Hospital, EsSalud, and the Metropolitan Polyclinic (EsSalud).

Disclaimer: the views expressed in this article are those of the author and do not necessarily reflect the official policy or position of the Department of the Navy, Department of Defense, nor the U.S. Government.

Conflict of interest: the authors report no conflicts of interest.

Copyright statement: Dr. Silvia Montano is an employee of the U.S. Government. This work was prepared as part of her official duties. Title 17 U.S.C. $\$ 105$ provides that 'Copyright protection under this title is not available for any work of the United States Government'. Title 17 U.S.C. \$101 defines a U.S. Government work as a work prepared by a military service member or employee of the U.S. Government as part of that person's official duties.

Received for publication: 12 October 2009. Revision received: 12 December 2009. Accepted for publication: 15 February 2010.

This work is licensed under a Creative Commons Attribution 3.0 License (by-nc 3.0).

(C) Copyright G.C. Navarro-Chumbes et al., 2010 Licensee PAGEPress, Italy

Neurology International 2010; 2:e6 doi:10.4081/ni.2010.e6

(Table 1). The Supercourse offers free access to a library of 4133 lectures in 31 languages, including clinical research methodology. ${ }^{15}$ The Universidad Nacional Mayor de San Marcos offers free access to lectures in epidemiology and clinical research methodology in Spanish, 
as does the Pan American Health Organization. ${ }^{16,17}$ The National Institute of Health offers an on-line Introduction to the Principles of Practice of Clinical Research to sites in Washington D.C., Mexico City, and Lima, Peru. ${ }^{18}$ The authors are not aware of any web-based certificate or diploma courses in clinical methodology.

In Peru, physicians who complete specialization training in neurology and register with the Peruvian Medical Association are considered as neurologists. In September 2004, 254 (16\%) of the 15,616 registered physicians in Peru were neurologists: 191 men and 63 women. The Peruvian Society of Neurology, Psychiatrics, and Neurosurgery regulates the training of neurologists. Physicians aspiring to become neurologists must provide medical care on a neurology ward for two years, attend conferences of the Peruvian Neurologic Society for two years, and submit a curriculum vitae for review by a committee composed of representatives from the Peruvian Medical Association and the Peruvian Neurologic Society. ${ }^{19,20}$ No assessment of barriers to clinical research training for Peruvian neurologists has been conducted. To better understand these barriers, we surveyed and interviewed neurologists regarding their perceptions of the needs and opportunities for enhancing clinical research in Peru.

\section{Materials and Methods}

A distribution of neurologists registered with the Peruvian Medical Association was obtained from the Medical College of Peru (Figure 1). Of the 254 neurologists registered with the Association, 185 (72.8\%) work in Lima. The two cities with the next greatest numbers of neurologists were Arequipa (16 neurologists) and Trujillo (21 neurologists). For this study, we had funding to support interviewing in Lima and one city in the provinces. Arequipa was chosen because it is the second largest city in Peru. In Lima, participating neurologists were recruited from the following sites: Institute of Neurological Sciences, Ministry of Health, E. Rebagliati EsSalud Hospital, Air Force Hospital, Stella Maris Private Hospital, and a private doctor's office; in Arequipa, neurologists were recruited from Honorio Delgado Hospital, Ministry of Health Hospital, Carlos Alberto Seguin EsSalud Hospital, III Yanahuara EsSalud Hospital, and EsSalud Metropolitan Polyclinic.

\section{Survey instrument}

The objective of our survey was to identify the following factors: level of training received in research methodology, importance of increasing research capacity in Peru; existing

Table 1. Web-based resources for neurology and clinical research methodology.

\begin{tabular}{|c|c|c|}
\hline Topic & University & Website \\
\hline Neuropathology & University of Oklahoma & http://moon.ouhsc.edu/kfung/JTYl/index.htm \\
\hline $\begin{array}{l}\text { Neuromuscular } \\
\text { diseases }\end{array}$ & Washington University & www.neuro.wustl.edu/neuromuscular/index.html \\
\hline Neurogenetics & $\begin{array}{l}\text { University of } \\
\text { Washington }\end{array}$ & www.ncbi.nlm.nih.gov/sites/GeneTests/review?db=GeneTests \\
\hline Neurosurgery & University of Maastricht & http://wiki.cns.org/wiki/index.php/Main_Page \\
\hline Neurology training & $\begin{array}{l}\text { World Federation } \\
\text { of Neurology }\end{array}$ & http://www.wfneurology.org/default.php \\
\hline Neurology training & $\begin{array}{l}\text { European Board } \\
\text { of Neurology }\end{array}$ & $\begin{array}{l}\text { http://www.uems-neuroboard.org/ebn//index.php?option } \\
\text { =com_wrapper\&Itemid= } 66\end{array}$ \\
\hline $\begin{array}{l}\text { Repository of clinical } \\
\text { methodology lectures }\end{array}$ & $\begin{array}{l}\text { Supercourse, } \\
\text { University of Pittsburgh }\end{array}$ & http://www.pitt.edu/ superl/ \\
\hline $\begin{array}{l}\text { Repository of clinical } \\
\text { methodology lectures }\end{array}$ & $\begin{array}{l}\text { Universidad Nacional } \\
\text { Mayor de San Marcos }\end{array}$ & http:/www.epiredperu.net/epired/ppt_list.htm (in Spanish) \\
\hline $\begin{array}{l}\text { Repository of clinical } \\
\text { methodology lectures }\end{array}$ & $\begin{array}{l}\text { Pan Amercian Health } \\
\text { Organization }\end{array}$ & http:/www.campusvirtualsp.org (in Spanish and English) \\
\hline
\end{tabular}

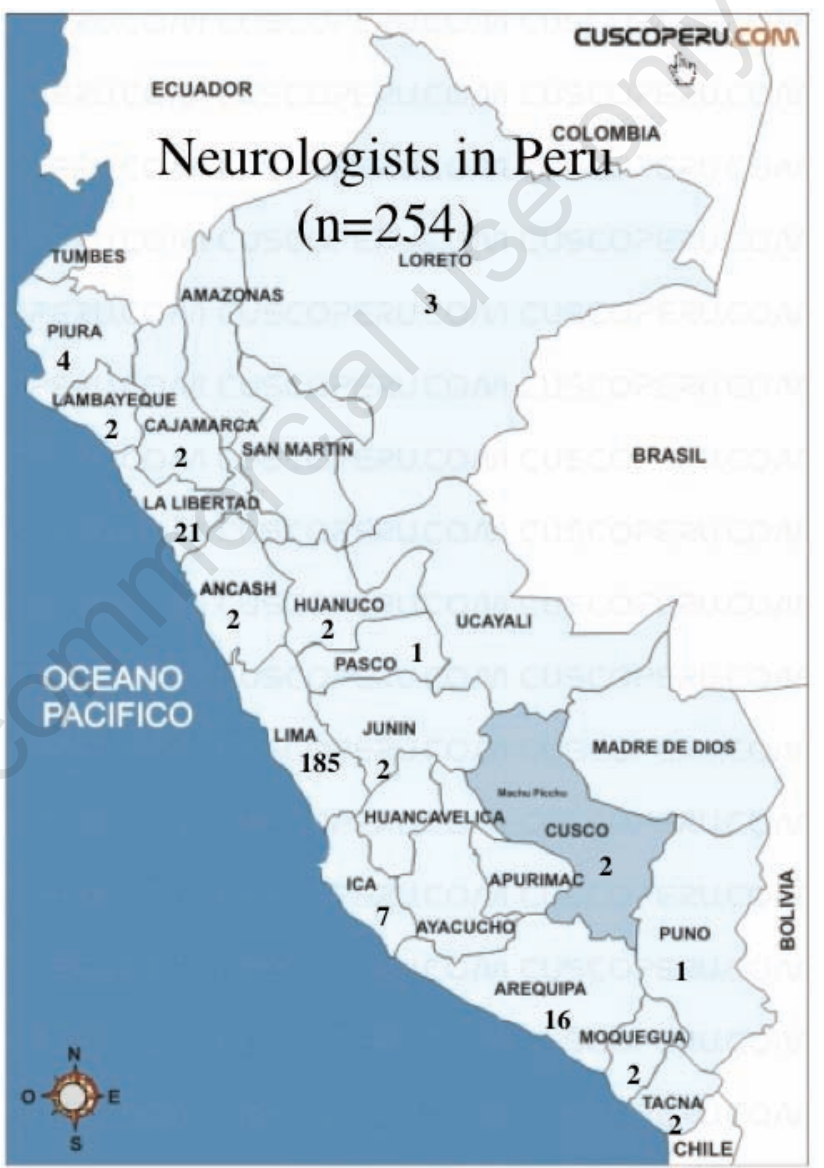

Figure 1. A distribution of neurologists registered with the Peruvian Medical Association.

barriers and potential solutions regarding research in neurology, priorities for training and infrastructure improvements for neurological research, priority topics for research in neurology, and best methods for providing training in research methodology.

To develop the survey instrument, a study neurologist and an epidemiologist interviewed two neurologists conducting clinical research in Lima to identify key topics in training and clinical research and better understand the barriers and needs encountered by neurologists interested in clinical research. They next developed questions to expand on these identified issues and met with the same neurologists to clarify ambiguous questions and terminology. Then a study interviewer trained in public health research was instructed regarding neurological terminology and how to administer this survey. Neurologists involved 
in the development of the survey were not interviewed in the final survey.

After obtaining permission from the chief of neurology at each site, the interviewer met with each neurologist at the site to invite him or her to participate. If a neurologist agreed to participate, the study interviewer obtained verbal consent and general demographic information and then explained that the first section of the survey regarding perceptions of research and training would be self-administered and anonymous. The interviewer was available to answer any questions, and the survey contained no identifying information other than noting the city where it was administered.

The second stage of the survey included an in-depth oral interview to capture additional information that required open-ended questions to avoid biased answering of questions. Oral interviews were recorded without personal identifiers and later transcribed. The written and oral surveys were administered in Spanish by the same interviewer.

Neurologists were asked to rate the level of training received in neurology and research using the following Likert-value scale:

1. None or scarce training

2. Little training

3. Some training

4. Adequate training

5. Excess training

NA None of the above.

Neurologists were asked to rate the importance of training in neurology and clinical research using the following scale:

1. Not important

2. Slightly important

3. Important

4. Very important

5. Extremely important

NA None of the above.

\section{Data analysis}

For the quantitative assessment, data were entered into an Excel spreadsheet and then translated into SPSS (Version 11.0 Chicago, Il, USA) for statistical analysis. Analyses of sociodemographic characteristics and topic rankings were performed using SPSS. For the qualitative assessment, transcribed information from each interview was reviewed to identify recurring themes. Answers then were organized into the following identified themes: problems in clinical research, potential solutions to identified problems, training priorities, needs for research training and capacity building, other professionals in need of training, types of training desired, and research topics of interest. Answers in each theme were analyzed for recurrent similarities, differences, and unique answers. Themes and answers were compiled and represented in textual or tabular form.

Table 2. Employment characteristics of Peruvian neurologists by age bracket.

\begin{tabular}{lccc} 
Agre(years) & $\begin{array}{c}\text { Distribution } \\
\text { of Age n (\%) }\end{array}$ & $\begin{array}{c}\text { Academic Position } \\
\text { n (\%) }\end{array}$ & $\begin{array}{c}\text { Yore than one job } \\
\text { n (\%) }\end{array}$ \\
$31-40$ & $22(45.8)$ & $21(43)$ & $21(100)$ \\
$41-50$ & $13(27.1)$ & $13(27)$ & $10(76.92)$ \\
\hline $51-60$ & $11(22.9)$ & $13(27)$ & $8(72.72)$ \\
Older than 60 & $2(4.2)$ & $1(3)$ & $0(0.00)$
\end{tabular}

Table 3. Perceived quality of current and future training needs.

\begin{tabular}{lll} 
Some training $($ score $<4)$ & Cuittle training $($ score $<3)$ & No or scarce training (score <2) \\
Data analysis & Development of research protocols & $\begin{array}{l}\text { Budget management } \\
\text { Situational analysis }\end{array}$ \\
Design of epidemiologic studies & Bioethics & \\
\hline Health economics & Data entry and management & \\
Investigational methodology & Scientific writing & \\
\hline Principles of biosafety & Critical analysis of scientific literature \\
Principles of biostatistics & Grant writing & \\
\hline Principles of epidemiology & Program analysis & Strategic planning \\
& Policy development & Training Needs $\quad$ Important (score 4-4.5)
\end{tabular}

\begin{tabular}{ll} 
Development of research protocols & Principles of epidemiology \\
Investigational methodology & Principles of biosafety \\
\hline Bioethics & Principles of biostatistics \\
Design of epidemiologic studies & Scientific writing \\
\hline Critical analysis of scientific literature & Budget management \\
Grant writing & Data entry and management \\
& Situational analysis \\
& Program analysis \\
& Policy development \\
\hline
\end{tabular}

\section{Results}

Between September 2004 and April 2005, 48 neurologists participated in written and oral surveys: 37 (20\% of neurologists) in Lima and 11 (69\% of neurologists) in Arequipa. Of the 254 neurologists in Peru, 48 (19\%) participated in the survey; $37(77 \%)$ were male and 11 (23\%) female. Most (42\%) neurologists in Lima were employed at the Institute of Neurological Sciences. More than half (54\%) of neurologists in Lima and Arequipa worked at more than one site, most in private clinics. Most (69\%) also taught residents or medical students, and nearly half had academic appointments (Table 2).

The topics with the lowest perceived level of training (less than "adequate" according to the rating scale) were: management of financial resources, situational analysis, data collection, program analysis for supervisors, needs assessment, strategic planning, and research program development. Epidemiology received the highest ranking of training topics. Clinical research topics rated as important (rating score $>4$ ) included: ethical conduct of research, research methods, research with vulnerable populations, and design of epidemiological studies (Table 3).

Neurologists identified the following research skills as highest priority: development of research hypotheses and protocols, needs assessment, situational analysis, data collection, program analysis, and strategic planning. Other important topics were epidemiology, quantitative and qualitative research methods, and statistics. To enhance the existing research infrastructure, neurologists suggested that institutions should provide neurologists with protected time and financial compensation to pursue research activities. Many neurologists also felt that the government should stimulate clinical research by creating a neurological disorders database for each region of the country, by coordinating efforts to improve training on research methods for health professionals, and by increasing wages to allow physicians to pursue research activities. The responses to some of the qualitative questions are listed below each question, by city.

Question 1: In your opinion, what are the main problems limiting clinical research in 
Peru?

Neurologists in Lima answered:

- Few hours are available for research as demands to perform clinical care are high.

- Time spent conducting research is usually not compensated, so physicians are not motivated to participate as they must earn a living.

- Hospitals are designed to provide clinical care and research is not a priority.

- Researchers have limited external economic support.

- Institutional support of research training is lacking.

- Research offices and resources to conduct research at hospitals to support neurologists interested in research are lacking.

- Research is not considered part of medical work or recognized as criteria for promotion.

- The health system does not address needs of the community.

- No information is provided by officials regarding national statistics for neurological disorders.

- Community Medicine and Public Health are not incorporated into medical school curricula.

Neurologists in Arequipa answered:

- Resources to conduct research are scarce and insufficient.

- Only universities in Lima have international collaborations and support.

- Professionals do not receive adequate training.

- Training in statistics is lacking.

- Interest in clinical research is limited.

- Educational and research opportunities are lacking.

- Time for participation in clinical research is limited by demands of clinical care activities.

Question 2: What are the potential solutions

to these problems?

Neurologists in Lima answered:

- Better training in research methods.

- Research methods courses should be offered by a tenured professor.

- Research projects should cover various fields, ranging from epidemiology to clinical trials.

- Everyone working in the health sector, at all levels, should be made aware of the importance of research to improving clinical care.

- Better compensation for clinical care to allow time to conduct research.

- More physicians should be hired to permit time to participate in research activities.

- Institutions and section chiefs should develop and run research programs.

- Institutions should provide compensation for participation in research activities.

- Better coordination of the health system.

- Improved collection of basic information regarding morbidity and mortality of neurological disorders.

Neurologists in Arequipa answered:

- Universities must seek international collaborations.

- Time should be made available to conduct research.

- Universities should include research methodology in medical school curricula.

- Institutions should provide resources for research.

- Physicians should be encouraged to perform clinical research.

- There should be collaboration between neurologists to conduct research.

- National statistics regarding neurological disorders should be available.

Question 3: In your opinion, what are the training priorities for Peru?

Neurologists in Lima answered:

- Scientific research methods for quantitative and qualitative research.

- Study design and protocol implementation.

- Grant application writing.

- Research and teaching.

- Epidemiology and statistics.

- Biology and immunology.

- Public Health.

Neurologists in Arequipa answered:

- Scientific research methods.

- Statistics.

Question 4: In your opinion, what forms of training would best meet your needs for clinical research training?

Neurologists in Lima answered:

- Distance learning courses via the internet.

- Courses.

- Workshops.

- Seminars.

Neurologists in Arequipa answered:

- Distance learning via the internet.

- Theoretical classes.

- Workshops.

- Self training.

- One-on-one training with a research mentor.

\section{Discussion}

Clinical neurological research in developing countries is essential for better understanding of endemic infections and diseases of regional and global importance, for integrating basic science discoveries into advances in patient care, and for advancing professional development. In Peru, neurologists identified the main barriers to participation in clinical research as: inadequate resources, inadequate methodological training, limited time to conduct research, lack of institutional support, absent national statistics on neurological disorders, and economic situations requiring they work more than one job. Not surprisingly, many of these barriers are similar to those confronted by neurology residents in the United States. ${ }^{21}$ Peruvian neurologists also felt that universities should help seek research funding through national and international collaborations.

One limitation of this study was the involvement of slightly less than $20 \%$ of Peruvian neurologists, thus limiting our ability to generalize our findings to all Peruvian neurologists. However, given the high likelihood that neurologists throughout the developing world face similar barriers to developing careers in clinical neurological research, our findings can be used to guide development of new clinical research training programs. Incorporating research methodology training with a practical mentored clinical research experience and protected research time provides the greatest hope for increasing clinical neurological research in Peru and perhaps in other developing world settings. ${ }^{8,21}$

Academicians have identified four essential elements of a successful clinical neurology research training program: i) a 2- to 3-year clinical research fellowship with appropriate courses in methodology; ii) protected time as a junior faculty to allow development into an independent researcher; iii) an environment with mentors who have successfully obtained research funding; and iv) a sufficient number of collaborators with existing research programs to provide junior faculty with clinical research opportunities. ${ }^{22}$ Although protected time and well-developed research programs are uncommon in Peru, neurologists are interested in clinical research and desire opportunities to participate in clinical research. Limited time to participate in traditional universitybased postgraduate training programs makes web-based courses and short conferences attractive training options. Web-based programs could provide training opportunities to locations with limited educational opportunities where neurologists have limited time for training. Increasing access to the internet throughout the world makes on-line training an attractive method for teaching clinical research methodology; collaborations between academic institutions and international neurological associations may provide the strongest partnerships for developing on-line diploma and certificate courses for training neurologists and other health professionals in clinical research methodology.

\section{References}

1. Sackett DL, Rosenberg WM, Gray JA, et al. Evidence-based medicine: what it is and what it isn't. Br Med J 1996;312:71-2. 
2. Chinnock P, Siegfried N, Clarke M. Is evidence-based medicine relevant to the developing world? Systematic reviews have yet to achieve their potential as a resource for practitioners in developing countries. Evid Based Complement Alternat Med 2005;2:321-4.

3. Haddad H, MacLeod S. Access to medical and health information in the developing world: an essential tool for change in medical education. Can Med Assoc J 1999;160: 63-4.

4. McMichael C, Waters E, Volmink J. Evidence-based public health: what does it offer developing countries? J Public Health 2005;27:215-21.

5. Kelly W, Randolph M, eds. Careers in clinical research. Obstacles and opportunities. Washington, DC: National Academy Press, 1994.

6. Horton R. Medical journals: evidence of bias against the diseases of poverty. Lancet 2003;361:712-3.

7. Pakenham-Walsh N, Mayosi BM. Where to practise evidence-based medicine? Lancet 2001;357:723-4.

8. Sitthi-Amorn C, Somrongthong
Strengthening health research capacity in developing countries: a critical element for achieving health equity. $\mathrm{Br}$ Med $\mathrm{J}$ 2000;321: 813-7.

9. Editorial. Rev Per Neurol 1997;3.

10. Ruiz JG, Mintzer MJ, Leipzig RM. The impact of E-learning in medical education. Acad Med 2006;81:207-12.

11. Chumley-Jones HS, Dobbie A, Alford CL. Web-based learning: sound educational method or hype? A review of the evaluation literature. Acad Med 2002;77:S86-93.

12. Hale LS, Mirakian EA, Day DB. Online vs. classroom instruction: student satisfaction and learning outcomes in an undergraduate Allied Health pharmacology course. J Allied Health 2009;38:e36-42.

13. Kash KM, Leas BF, Clough J, et al. ACGME competencies in neurology: web-based objective simulated computerized clinical encounters. Neurology 2009;72:893-8.

14. Ochoa JG, Wludyka P. Randomized comparison between traditional and traditional plus interactive Web-based methods for teaching seizure disorders. Teach Learn Med 2008;20:114-7.

R. 15. LaPorte R, Linkov F, Lovallekar M, et al.
Supercourse: Epidemiology, the Internet and Global Health [online]. Available at: http://www.pitt.edu/ super1/. Accessed December 9 .

16. Alarcon JOAV. Epired [online]. Available at: http://www.epiredperu. net/epired/ppt_list.htm. Accessed December 9.

17. PAHO. Campus Virtual de Salud Pública [online]. Available at: http://www.campusvirtualsp.org/.

18. NIH. Introduction to the Principles of Practice of Clinical Research [online]. Available at: http://www.cc.nih.gov/training/training/ippcr.html. Accessed December 8.

19. Editorial. 63 Anos de la Sociedad Peruana de Neurologia. Rev Per Neurol 2001;7.

20. Mariategui J. 60 Anos en la Historia. Rev Neu Psiquiat 1997;60:1-2.

21. Hauser SL, McArthur JC. Saving the clinician-scientist: report of the ANA long range planning committee. Ann Neurol 2006;60:278-85.

22. Griggs RC. Careers in academic neurology in the decade of the brain. Ann Neurol 1994;35:753-8. 